\title{
A PRÁTICA TROVADORESCA DE BEATRIZ DE DIA: AFIRMAÇÃO IDENTITÁRIA E A TRANSFORMAÇÃO DO CONCEITO DE AMOR CORTÊS
}

Ana Luiza Mendes Roberta Bentes

Resumo: $O$ presente trabalho tem como objetivo analisar a produção trovadoresca de Beatriz de Dia (1140-1212), uma das mais famosas trovadoras que se tem notícia. $O$ estudo de duas das quatro composições que dela nos chegaram se faz a partir da perspectiva da história das mulheres, com o intento de indagar a visão de que as mulheres medievais não tinham possibilidades de ações naquela sociedade. Desse modo, a escolha das fontes não se fez de modo ingênuo. A literatura foi por um grande período da história um campo eminentemente masculino, cabendo às mulheres um papel marginalizado. Essa característica também pode ser visualizada na Idade Média, cujo caráter misógino é bastante evidente, porém é possível identificar vozes femininas que permitem estabelecer outros vieses para pensar sobre relação com a sociedade. Nesse contexto, a produção trovadoresca é de suma importância, uma vez que gira em torno, entre outros temas, do chamado amor cortês, considerado por muitos estudiosos como um gênero literário que expressa um jogo eminentemente masculino no qual a participação da mulher em uma posição superior é apenas um recurso de ficção e retórica. No entanto, a existência de trovadoras contribui para questionar esse posicionamento, assim como a própria produção de Beatriz, uma vez que ela subverte as regras literárias ao estabelecer um diálogo entre o amor e o desejo que não permanece no mundo abstrato, sugerindo a sua efetivação. Ainda que não possamos deixar de lado o caráter ficcional que integra toda literatura, é importante ter em mente que ela não surge do nada, ou seja, ela tece sua trama a partir do que é verossímil. Assim sendo, mesmo que não possamos comprovar que o amor cantado por Beatriz foi, de fato, realizado, temos a sugestão de que isso poderia ser desejado, revelando uma aspiração feminina que extrapola concepções de comportamento homogeneizantes e redutores.

Palavras-chave: Trovadoras. Beatriz de Dia. Amor cortês. Literatura Medieval. Mulheres no medievo. 
Abstract: The present paper aims to analyse the troubadour lyrics of Beatriz de Dia (1140-1212), one of the most famous trobairitz ever known. The study of two of the four compositions that survived is made from the perspective of the Women's History, with the intent of questioning the view that medieval women did not have the possibility of action in society. Thus, the choice of sources was not made in a naive way. Literature was, for a long period of History, an eminently male field, with women playing a marginalized role. This characteristic can also be seen in the Middle Ages, whose misogynist character is quite evident, but it is possible to identify female voices that allow other biases to think about the action of women in the medieval society. In this context, troubadour production is of paramount importance, since it revolves around, among other themes, the so-called courtly love, considered by many scholars as a literary genre that expresses an eminently masculine game. Which the participation of women in a higher position is just a resource of fiction and rhetoric. However, the existence of trobairitz contributes to question this idea, as well as Beatriz's production, since it subverts the literary rules by establishing a dialogue between love and desire that does not remain in the abstract world, suggesting its consummation. Although we cannot ignore the fictional disposition that integrates all literature, it is important to keep in mind that it does not arise from nothing, that is, it weaves its plot from what is credible. Therefore, even though we cannot prove that the love sung by Beatriz was, in fact, realized, we have the suggestion that this could be desired, revealing a feminine desire that goes beyond homogenizing and reducing conceptions of behavior.

Keywords: Trobairtiz. Beatriz de Dia. Courtly love. Medieval Literature. Medieval Women.

Ao desenvolver pesquisas sobre a história da literatura é comum nos depararmos com uma quantidade massiva de autores homens, enquanto as mulheres pairam como que em notas de rodapé, esparsas, como se essa atividade fosse exclusiva da esfera masculina. De fato, por muito tempo o pensamento corrente era o de que a voz e a palavra não eram 
ações das quais as mulheres deveriam ser protagonistas, pois seu espaço deveria ser o do âmbito privado, dos afazeres domésticos, da criação dos filhos. Assim, é preciso muito esforço e dedicação para identificar nos escombros da História as suas vozes e letras que se perderam nos meandros das sociedades patriarcais e misóginas, contribuindo para a não inserção delas nos cânones da história e da literatura.

Com o advento da história das mulheres, ocorrido a partir da década de 1960, instigado pelos movimentos políticos, sociais e culturais do período, incluindo-se o movimento feminista, tem-se o questionamento do apagamento das mulheres ao longo da história e da diminuição da sua participação em diferentes esferas, transmitindo a ideia de que elas estavam inseridas passivamente na prática de sua restrição social. Tal concepção é mais cristalizada conforme nos deparamos com períodos mais longínquos, como a Idade Média, uma vez que as fontes são mais escassas, restando, muitas vezes, trabalhar apenas com fragmentos ou indícios de que essas mulheres eram muito mais complexas e atuantes do que comumente a história transmitiu.

Tratando-se das mulheres medievais é necessário, num primeiro momento, desconfiar das fontes, uma vez que elas foram majoritariamente escritas por homens. Dessa forma, elas 
não são neutras e tecem narrativas sobre as mulheres a partir de uma percepção que pode ser depreciativa, uma vez que elas seriam as responsáveis pelos males destinados ao homem.

Georges Duby salienta que os discursos medievais sobre as mulheres, sobretudo os provenientes do âmbito religioso, devem ser ponderados, uma vez que eles partem do medo que esses homens tinham das mulheres. No entanto, a misoginia não era prerrogativa masculina. Estava presente na concepção de mundo da época, fazendo com que mulheres também disseminassem essa visão, como atesta o discurso de Heloísa (1090-1164) ou o de Hildegard von Bingen (1098-1179) que discorrem sobre a fraqueza da mulher, demonstrando que homens e mulheres compartilhavam de visão negativa sobre o feminino.

Tudo isto é repetido com tal insistência e tão fastidiosamente na Idade Média, que se acaba persuadido do penoso sentimento de imobilidade, da perenidade de um discurso. [...] De fato, o perigo é tratar essas ideais, essas representações, como se a estabilidade e aquiescência que elas suscitam, até nas mulheres, fossem verdadeiras e testemunhassem a realidade de sua prática social. Durante muito tempo, os historiadores da Idade Média entraram nesse jogo.

Mas podem-se ver as coisas de outra forma e sacudir o entorpecimento fascinado ou resignado que nasce da repetição. (KLAPISCH-ZUBER, 2017, p. 158) 
Essas afirmações devem ser investigadas criticamente, uma vez que revelam um importante aspecto do período medieval. Entretanto, também é preciso ir além e esmiuçar outros testemunhos que permitem identificar um discurso que possibilita identificar uma complexidade de acepções sobre o papel das mulheres na sociedade medieval, reveladas pelas diferentes imagens com as quais elas podem ser relacionadas: de Eva a Maria no discurso religioso, e outras diferentes facetas, soldadeiras, artesãs, escritoras, se nos atentarmos para outras esferas em que as mulheres podem ser vistas como seres atuantes. Assim sendo, pode-se notar que ocorrem diferentes contextos, demonstrando que o pensamento medieval não era estático, indicando novas concepções sobre o papel das mulheres naquela sociedade.

Em relação às representações presentes no discurso religioso é interessante notar que as relações entre as mulheres com Maria Madalena e Maria podem ser observadas a partir do século XI, no qual há o desenvolvimento do culto à primeira se estendendo pelo século XII com o fomento do culto à Virgem Maria, estimulado por Anselmo da Cantuária (1033-1109) e Bernardo de Claraval (1090-1153), grandes responsáveis pela disseminação da mariologia medieval. No século XII existiam variadas narrativas sobre Maria que 
exploravam seu sofrimento e de seu filho, promovendo a humanização de ambos em consonância com a nova espiritualidade pensada e vivenciada nesse período.

Esse também é o momento em que se observa a disseminação da cultura cortês, dentro da qual se insere o chamado amor cortês (fin'amors), gênero literário inserido na nova concepção de mundo e sociabilidades e que coloca a mulher em uma posição de destaque. Tal denominação foi cunhada em 1893 por Gaston Paris (1839-1903) para definir os contornos do discurso amoroso que coloca o Amor como uma qualidade superior por meio do qual a mulher é alçada a uma posição superior ao do homem que, apaixonado, coloca-se como seu vassalo amoroso e canta seu sentimento com uma retórica amorosa rica em metáforas, transitando entre a idealização e o amor carnal.

Há em torno dessa expressão cultural uma discussão acerca do papel que ele exerceu em relação à visão das mulheres. Segundo Georges Duby (2011), não é possível falar de uma promoção da mulher, uma vez que ele vê o amor cortês como um jogo no qual a mulher é apenas um chamariz, uma peça por meio da qual os jovens são ensinados a controlar seus impulsos. Assim sendo, essa seria uma literatura de evasão, feita de homens e para homens. 
Na mesma perspectiva, John F. Benton (1972, p. 19-42) afirma em seus estudos que não parece ter havido uma mudança dramática nos costumes sexuais ou sociais no sul da França ${ }^{1}$ que poderia corresponder a uma aplicação das ideias sobre o amor cantadas pelas músico-poetas.

Geralmente a mulher que era adorada nas cortes de amor não era a mesma que se fazia dona do lar ou aquela a quem concedia sua mão o serviçal cavaleiro, e só este fato convertia estas relações amorosas num jogo de galanteria ou as degradava para o plano da simples paixão, que quase nunca servia de ponto de partida para uma estimação mais elevada da mulher. (VISCARDI apud SPINA, 1991, p. 23)

Da mesma forma, Danielle Régnier-Bohler (2017, p. 57) enfatiza que a triangulação amorosa presente nas narrativas poéticas (dama-trovador-marido) seria uma transposição da feudalização da sociedade que, ao elevar a dama ao status de senhor, por meio de um código feudal, teria a função de controlá-la. Nessa perspectiva, Christiane Marchello-Nizia defende que a ética cortês da relação entre o cavaleiro e sua amada teria "uma função civilizadora de

1 A região do que hoje seria o Sul da França, assim como parte da Catalunha e do noroeste da Itália foi dominado pela cultura occitana, assim como pela sua língua, o Langue d'Oc. O Langue d'Oc é uma língua românica, e além de ter permeado a poesia, esta também estava presente nas documentações jurídicos, científica (tratados de medicina) e administrativas da região que se falava. O Langue d'Oïl é a língua falada na região ao norte do território francês atual e tem origem no braço galo-românico, e é a língua mais próxima do francês arcaico e atual. Tanto o termo Langue d'Oc e Langue d'Oïl tem o mesmo significado: "língua do sim", assim como o Língua di Si presente na Sicília. 
integrar o cavaleiro na sociedade feudal, compartilhando e apresentando seus valores" (1995, p. XXXIX).

De acordo com essa instrumentalização feudal da poesia, a mulher arcaria com uma responsabilidade gigante sobre o homem: o de educá-lo e o satisfazê-lo de diferentes formas, em diferentes instâncias² (BRUCKNER, 1992, p. 865-891), reforçando assim, um estereótipo de mulheres voltadas para o contexto da esfera privada, mostrando-se limitada, passiva e figurativa, além de trazer a característica dominante da cultura feudal do Langue d'Oïl para a produção lírica ${ }^{3}$.

Por outro lado, é importante pensar que o amor cortês não se constitui apenas como literatura, mas também como fenômeno social.

Isso quer dizer que o amor cortês não se revela apenas como um fenômeno literário, distanciado do imaginário e das relações sociais feudais características do sul da França.

2 Espera-se que o domna acabe com o sofrimento de seu amante poético e recompense seu serviço paciente em música com a maior alegria da satisfação do amor - a joi. A recompensa poderia ser a realização do sexo, mas também poderia ser um olhar, ou um presente, como luvas.

3 A região occitânica durante o século XII e XIII é marcada por uma administração e conhecimento jurídico que empregava o reconhecimento dos vilãos e potenciais mercadores presentes gerando um estímulo para o progresso econômico. A Occitania mira na possibilidade de trazer uma segurança jurídica necessária para uma reinvenção do comércio com os territórios de interesse e aos próximos, assim como um direito individualista com base jurídica adequada às atividades do local, livre das limitações comunitaristas fortemente presentes no regime feudal que é encontrado no Langue d'Oïl. A presença deste Direito Justiniano se inicia com o Renascimento do século XII. Se ao Norte, seu direito à terra gerou a sucessão pela progenitura, no Sul as glebas eram divididas em partes iguais entre os herdeiros, além de possibilitar também a posse de terras às mulheres e às igrejas (RODRIGUES, 2021). 
Às condições políticas e econômicas favoráveis à eclosão do amor e da cortesia se junta o Renascimento do século XII, que, ao mesmo tempo que as condições econômicosociais, forma o universo, o plano possível para o aparecimento do amor.

No interior desse plano é possível incluir um certo número de variáveis ao aparecimento desse amor sentimental e sensual, inédito na experiência do Ocidente. (PEREIRA, 2013, p. 92-93)

Uma dessas variáveis é o fato de que "aquela sociedade estava preparada para receber um discurso sobre as mulheres" (PEREIRA, 2013, p. 95), as quais, como aponta Jean Flori, podiam "pleitear justiça, herdar, governar, e talvez até reinar e não pode, por direito, ser casada contra a vontade" (2005, p. 142).

Como exemplo dessa ação de exercício de poder das mulheres temos uma carta de Eleanor d'Aquitânia (11221204), demonstrando a sua capacidade de administração, regência e justiça para com amigo, primo ${ }^{4}$ e cavaleiro poitevino que servia o Rei Ricardo Coração de Leão (11571199), Andreas Chauvigny (1150-1202):

Eleanor, pela graça de Deus, rainha da Inglaterra, duquesa da Normandia e Aquitânia, condessa de Anjou, aos arcebispos, bispos, condes, viscondes, barões e todos os

4 Andreas era o segundo filho de Pierre-Hélie de Chauvigny e Haois de Châtellerault. E sua mãe tia-avó do Rei Ricardo. 
que verão o presente escrito, futuro bem como presente, saudação. Você deve saber que demos, concedemos e confirmamos por esta nossa presente carta, ao nosso querido amigo e parente Andreas de Chauvigny e seus herdeiros, todo o feudo de Sancta Severa, e as homenagens e lealdades do referido feudo, e tudo o que temos lá. Por isso desejamos e ordenamos firmemente que esse mesmo Andreas e seus herdeiros tenham dito feudo com suas homenagens e lealdades e o possuam em perpetuidade com todos os seus pertences, livremente, totalmente, totalmente, com honra. E para que este nosso dom continue firme e intacto no futuro, o reforçamos com a proteção do nosso selo e a assinatura de testemunhas. Com estas testemunhas: Robert, conde de Leicester, Baldwin, conde de Aumale, Gerard de Fourneval, William de Estain, Godfrey de Celle, William Marshal, conde de Pembroke, Hugo de Fontenelle, William Torpin, Elias de Sancta Severa, que estavam presentes e fez uma homenagem ao dito Andreas diante de todos. Datado em Le Vaudreuil pela mão de Roger, nosso capelão, no 1199 ano da encarnação do Verbo. (EPISTOLAE, 2021)

5 EPISTOLAE: MEDIEVAL WOMEN'S LETTERS. Eleanor Rainha Da Inglaterra - Carta de Leonor (1199). Disponível: https://epistolae.ctl.columbia.edu/letter/1329.html. Data de 24 de Fevereiro de 2021. No original em latim: "Alienor, Dei gratia regina Anglie, ducissa Normannie, Aquitanie, comitissa Andegavie, archiepiscopis, episcopis, comitibus, vicecomitibus, baronibus, et omnibus presens scriptum inspecturis, tam presentibus quam futuris, salutem. - Noveritis nos dedisse et concessisse, et hac presenti carta nostra confirmasse, karissimo amico et consanguineo nostro Andree de Calvigniaco et heredibus suis totum feodum de Sancta Severa, et homagia, et ligiamenta predicti feodi, et quicquid ibidem habebamus. - Quare volumus et firmiter precipimus ut idem Andreas et heredes sui predictum feodum, cum homagiis et ligiamentis, habeat et in perpetuum possideat libere, integre, plenarie, honorifice, cum omnibus pertinentiis suis. - Et ut ista donatio nostra firma et illibata futuris temporibus perseveret, eam sigilli nostri munimine et testium subscriptione roboravimus. Hiis testibus: Roberto comite Legrecestie, Baduwino comite de Albamarla, Girardo de Fornivalle, Willelmo de Stagno, Galfrido de Cella, Willelmo Marescallo comite de Penbroc, Hugone de Fontenellis, 
É sintomático analisar a carta de Eleanor que, para além do seu poder enquanto rainha, também é lembrada por sua relação com o movimento trovadoresco, visto ser neta do primeiro trovador conhecido. Guilherme IX, Duque d'Aquitânia e Conde de Poitiers (1071-1127) dá início no século XI ao chamado amor cortês, relacionado com a expressão cultural da nobreza que se vincula com o ideal de cortesia, sugerindo uma arte de viver que implica em polidez, refinamento dos costumes e honra cavaleiresca (LE GOFF, 2011, p. 229), e pode ser observado em diferentes regiões, como na Península Ibérica, onde ganha contornos próprios sem a participação de autoras como no trovadorismo occitano ${ }^{6}$.

A existência de trovadoras na produção occitana pode sugerir um reforço na importância da leitura, no consumo cultural e na valorização do amor lírico fortemente marcado nessa classe social, permitindo que a região do Langue $d^{\prime} O c$ criasse uma identidade poética singular. A presença e

Wilhelmo Torpin, Helia de Sancta Severa, qui presens erat et coram omnibus homagium fecit predicto Andree. - Data apud Vallem-Rodolii per manum Rogeri capellani nostri, anno Verbi incarnati millesimo centesimo nonagesimo nono".

6 Devemos pensar na ideia de Occitanico e não Provençal, como podemos encontrar amplamente em muitos textos da época - a Provença seria muito ampla neste recorte temporal -, pois ao trazer a ideia de Provençal daríamos a impressão de delimitar a produção cultural à região da Provença, o que não é a realidade. Ainda que Beatriz de Dia tenha vivido e falecido na região da Provença, o registro de suas cantigas está em Occitano. Utilizamos a denominação de Occitano por abranger todas as variações, extensões e riquezas da língua. (ANGLADE, 1921, p. 10; BEC, 1986, p. 8). 
sobrevivência de um corpus feminino occitanico que versa sobre amor, frisando seus nomes deve estar ligado com grau de independência pessoal que essas mulheres vivenciaram.

Assim, o amor cortês pode ser compreendido como uma valorização e defesa de um modo de viver, da memória e dos valores socioculturais (BENTES, 2019, p. 110) da região. Não seguindo um padrão e idealização única do amor, seria, assim, uma manifestação plural da narrativa (BENTES, 2020), incentivando uma leitura e escrita subjetiva e pessoal do sobre o amor, corroborando com a hipótese do início de uma individualidade nesse período. O pertencimento a um grupo social era extremamente importante, "pois na Idade Média imperava o coletivo que, contudo, poderia ceder um pouco de espaço para uma individualidade" (MENDES, 2018, p. 80) que mesclava as regras do mester trovadoresco com características pessoais (MENDES, 2018, p. 179).

Evidente que não podemos esquecer do caráter misógino presente no pensamento medieval e que uma das características do amor cortês é a idealização da mulher amada, compreendida por alguns autores como sendo uma essência, desprendida de uma realidade empírica. No entanto, essa literatura, nascendo no contexto de legitimação identitária da nobreza frente à burguesia nascente, deve 
também ser pensada como um modo de pensar que se estende a práticas de comportamentos que permite a singularidade da produção occitana feita também por mulheres, o que indicaria que elas tinham certo destaque, como sugere Duc de la Salle de Rochemaure ao indicar que o ensino para essas mulheres deveria ser diferenciado, sendo versado "na leitura de alguns romances, na arte do verso e da música, e no talento da conversa e da boa companhia" (1910, p. 416).

Nesse contexto encontram-se as trobairitz, trovadoras do sul da França e as troveresses, "trouveiras" do norte, cujas autorias são temas de grandes discussões que envolvem questões relacionadas ao gênero da autoria. Esse motivo pode ser uma das explicações para o fato de que são poucas as composições trovadorescas produzidas por mulheres que chegaram até nós: 11 cansós $^{7} ; 16$ tensós ${ }^{8} ; 3$ sirventeses ${ }^{9}$; 1 pranto $^{10}$; 1 alba $^{11}$ e 2 fragmentos (STEPHENS, 2000 , p. 23). De 20 trovadoras conhecidas, apenas Beatriz de Dia (1140-1212) e Na Castelloza (século XIII) têm mais de uma composição atribuídas a elas e somente 1 cantiga, de

\footnotetext{
7 Pelo conteúdo se relacionada com a cantiga de amor e era o gênero mais comum.

8 Debate poético.

9 Cantiga satírica de cunho político.

10 Cantiga que contém um lamento pela morte de alguém.

11 Cantiga que narra eventos desenvolvidos durante o amanhecer.
} 
Beatriz, "A chantar m'er de so q'ieu no volria", sobreviveu juntamente com a melodia.

Esses números parecem infinitamente insignificantes perto da quantidade de cantigas compostas por homens que a tradição conservou, no entanto, elas são significativas, pois indicam que algumas mulheres se posicionaram numa esfera dominada pelo masculino. Além disso, a participação delas como autoras contribui para pensar em uma faceta diferente acerca do amor cortês ser um jogo puramente literário, idealizado e masculino. Essas mulheres estavam inseridas no ambiente cortês, ou seja, receberam essas informações e atualizaram o seu discurso. Assim, as vozes das trovadoras contrapõem a tradição centrada no masculino que idealizavam a mulher como um ser inacessível e a transformavam em um objeto de desejo passivo. Ao lançarem suas vozes na cena trovadoresca, as trovadoras transformam o ideal passividade em uma quimera a ser descontruída.

É sintomático, portanto, analisar a forma da poesia dessas trovadoras, assim como suas representações imagéticas. Beatriz (Figura 1) e Na Castelloza comungam de algumas características em comum, como o uso da primeira pessoa do singular e marcas de posse na sua escrita e ambas são 
representadas em suas iluminuras declamando, interpretação feita a partir dos gestos de suas mãos que remete ao sinal de discurso pessoal, não escrito, portanto, confirmando o costume da oralidade e afirmando seu papel de trovadoras. Além disso, há referências de que elas foram reconhecidas mecenas (BRUN, 2014, p. 75-76).

Então, graças aos textos das trobairitz, temos uma visão do Fin'amor através da sua vivência. Poderíamos nos perguntar se os textos delas não poderiam ser uma resposta feminina à letra lírica, uma resposta não formulada sob a forma de uma missiva, mas sob a forma de peças líricas que assumem a forma e o pano de fundo dessa poesia criada por homens, para os homens. No entanto, não podemos dizer que elas foram consideradas iguais aos seus pares ou que elas se consideravam assim, e muito menos superior. Nos seus textos, descrevem-se frequentemente como "vítimas". (BRUN, 2014, p. 78-79) $)^{12}$

Beatriz de Dia é a trovadora mais aclamada no meio acadêmico por se tratar de uma personagem que teve o registro de maior corpus conservado, totalizando quatro composições: "Ab joi et ab joven m’apais”, "Fin joi me don'

12 No original: “Ensuite, grâce aux textes des trobairitz, nous avons une vision de la Fin'Amor telle qu'elle était vécue et décrite par elles. Nous pourrions nous demander si leurs textes ne pourraient pas être une réponse féminine à la lyrique troubadouresque, une réponse non pas formulée sous forme de missive mais sous forme de pièces lyriques reprenant la forme et le fond de cette poésie mise en place par des hommes et pour des hommes". Cependant, nous ne pouvons pas dire qu'elles étaient considérées comme égales à leurs pairs ou qu'elles se considéraient ellesmêmes de cette façon, et encore moins comme supérieures. Dans leurs textes, elles se décrivent très souvent comme des "victims". Tradução de Roberta Bentes. 
alegranssa", "A chantar m'er de so qu'ieu non volria" e "Estât ai em greu cossirier". Sua vida ${ }^{13}$ no Cancioneiro $\mathrm{K}^{14}$ assim a descreve: "A Condessa de Dia que ela era a esposa de Guillem de Peitieus, que ela era uma bela e boa senhora, e que se apaixonou por Raimbaut d'Aurenga [Orange], que inspirou seus muitos belos poemas"15. Essa informação transmitida por um dos autores do Cancioneiro (BURGWINKLE, 1999, p. 252-253) ${ }^{16}$, Uc de Saint Circ atua como uma introdução da autora das cansós que são apresentadas na sequência. Notase que tal descrição também usa informações presentes nas razós ${ }^{17}$ e nas cantigas. Esse texto, portanto, trata-se de uma representação da personagem que viveu no século XIII que é retomada no Cancioneiro do século XIV.

\footnotetext{
13 Pequeno relato biográfico.

14 Produzido no século XIV. É dividido em uma tabela que classifica os gêneros líricos e organiza cada um por meio das cantigas pertencentes de cada trovador. Esse tipo de classificação aparenta demonstrar o grau de influência, status e poder de cada trovador, ou pode estar relacionado com o gosto daquele que encomendou o Cancioneiro. Nos fólios seguintes, encontra-se o texto do cancioneiro. Este texto segue uma diagramação específica e um certo padrão: separando topograficamente os textos, encontram-se o nome do trovador em rubrica (anotações em vermelho), uma iluminura que permeia o formato de uma letra maiúscula inicial do texto, identificando quem seria, além de números romanos identificando seu posicionamento dentro do index no início do Cancioneiro. Logo abaixo, escrito com pigmentação negra, tem-se o registro das cantigas, e na mesma coloração seguem suas razós. (BENTES, 2019).
}

15 No original: “La comtessa de Dia si fo moiller d'En Guillem de Peitieus, bella domna e bona. Et enamoret se d'En Raembaut d'Aurenga, e fetz de lui maintas bonas chanssos e bellas, segon que vos poiretz vezer et entendre aissi" (CHANSONNIER, [s.d]).

16 Na vida de Bernart de Ventadorn encontramos a informação que quem teria elaborado a vida, seria Uc de Saint Circ. Mas também devemos dizer que na vida de Peire Cardenal encontramos a autoria de Miquel de la Tor.

17 Compreendidas como as razões para a escrita das cantigas, ou seja, uma espécie de crítica literária. 
Figura 1 - Comtessa de Dia no Cancioneiro K na Bibliothèque National de France - f. 126 v.

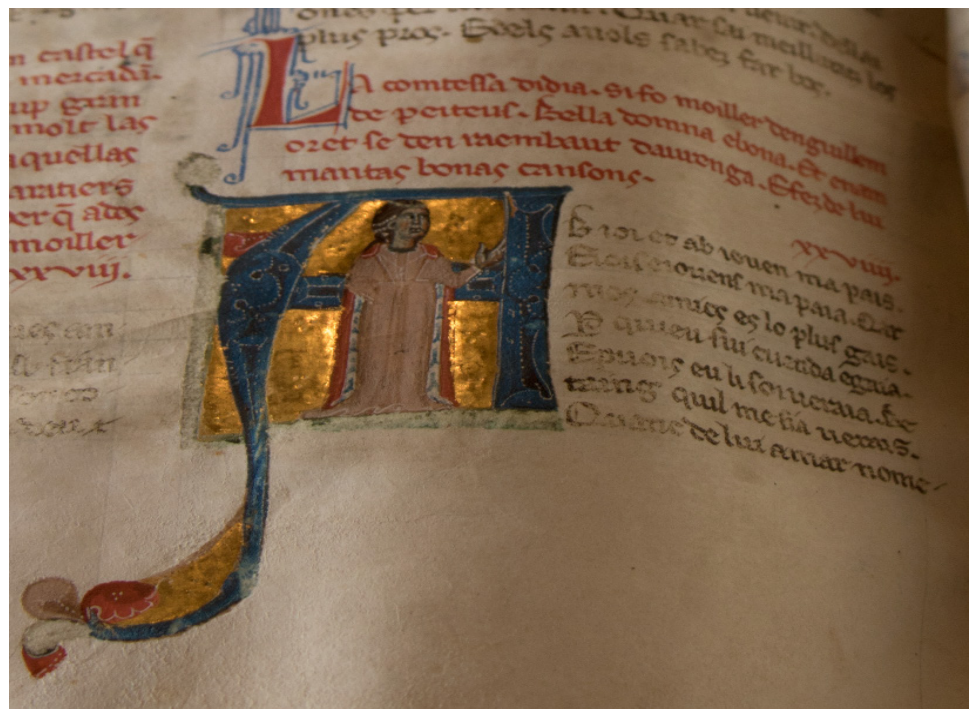

Fonte: Acervo pessoal da autora Roberta Bentes.

O Cancioneiro não ajuda os pesquisadores a descobrirem quem é Beatriz, visto que não trazem o nome da personagem. Desse modo, surgem possibilidades de acordo com o recorte histórico de seu título, região e o conteúdo de suas cantigas (BLAKESLEE, 1991, p. 314-315), podendo ser ela identificada, de acordo Walter Pattison (1952, p. 27-30), com Beatriz de Dia ou Isoarda de Dia e com Phillipa Fay, de acordo com Oskar Schultz-Gora (1888, p. 9).

A primeira hipótese diz que teria sido Beatriz filha de Guigues IV, delfim de Viennois, região perto de Dia ou de 
Isordo II, Conde de Dia e esposa de Guillem II de Peitieus ${ }^{18}$, conde de Valentinois, que teria posses perto do condado de Dia. A segunda hipótese trata-se de Isoarda (?-1212 ou 1214), filha do Conde de Dia e mulher de Raimon d'Agout (1130-1203), que viveu no recorte histórico de Raimbaut IV (?-1214). Por fim, a terceira hipótese versa sobre Phillippa Fay (1175-1251), esposa de Aymar II, Conde de Valentinois e Dia. Contudo, baseado em documentos existentes, nenhuma identificação definitiva parece ser possível, apesar da análise formal de Angelica Rieger (BRUCKNER et al, 2000, p. XXXIII) das cansós da condessa serem identificadas na segunda metade do século XII, associando-a por meio de evidência intertextual com o círculo de troubadours que incluem Raimbaut d'Aurenga (1147-1173), Bernart de Ventadorn ( 1130-c.1200) e a trobairitz Azalaïs de Porcairagues (final do século XII).

De acordo com Merritt Blakeslee (1991, p. 314-315), a interpretação que se têm de sua vida e da proximidade geográfica de Dia (comuna da região do Auvergne-RhôneAlpes) e Aurenga ${ }^{19}$ (comuna da região de Provence-AlpesCôte d'Azur), terra de seu suposto amante, é tradicionalmente feita a partir de sua tensó "Amics, em gran consirier" que

\footnotetext{
18 Leia-se como Poitiers na contemporaneidade.

19 Leia-se como Orange na contemporaneidade.
} 
teria sido feita para o trovador Raimbaut d'Aurenga. Porém, a precisão história de sua vida é suspeita, visto que nesta cantiga o trovador é identificado apenas como Raimbaut, o que nos leva a interpretação de dois possíveis personagens: o trovador Raimbaut d'Aurenga (morto em 1173) e talvez o seu sobrinho-neto Raimbaut IV (morto em 1214). Alternativamente, não seria impossível que Uc de Saint Circ, notando a temática e similitude linguística entre a tensó e as cansós, tenha inventado uma ligação entre os dois ${ }^{20}$. Portanto, sugere-se que a vida deva ser lida metaforicamente, na qual Raimbaut e Guillem seriam representações de dois estilos de poesia praticadas pela trovadora (HUCHET, 1983, p. 62-63).

No entanto, o que nos interessa nesse artigo, é a forma como a trovadora desenvolve suas composições com o intuito de afirmar sua condição de nobre e de autora. Assim, em sua cantiga "A chantar m'er de so qu'ieu non volria", ela reforça seu status de nobre e suas qualidades, algo necessário em uma sociedade misógina e que assiste às mulheres adentrando em áreas consideradas fora do seu âmbito.

20 Devemos salientar que as informações escritas e descritas nas vidas dos trovadores podem ou não ser precisas, podendo ocorrer de fato algumas incoerências ou informações, assim como também podemos notar um forte diálogo com a produção literária dos trovadores. 
A chantar m'èr de ço q'ieu no volria

I

A chantar m'er de so qu'ieu no volria, tant me rancur de lui cui sui amia car eu l'am mais que nuilla ren que sia;

vas lui no•m val merces ni cortesia, ni ma beltatz, ni mos pretz, ni mos sens, c'atressi m sui enganad'e trahia cum degr'esser, s'eu fos dezavinens. II

D'aisso $m$ conort car anc non fi faillenssa,

amics, vas vos per nuilla captenenssa; anz vos am mais non fetz Seguis Valenssa,

e platz mi mout qez eu d'amar vos venssa,

lo mieus amics, car etz lo plus valens; mi faitz orguoill en digz et en parvenssa, et si etz francs vas totas autras gens. III

Meravill me cum vostre cors

s'orguoilla,

amics, vas me, per q'ai razon queu $\bullet m$ duoilla;

non es ges dreitz c'autr'amors vos mi tuoilla,

per nuilla ren que us diga ni acuoilla; e membre vos cals fo I comensamens de nostr'amor! Ja Dompnidieus non voilla

q'en ma colpa sia I departimens! IV

Proesa grans q'el vostre cors s'aizina e lo rics pretz q'avetz m'en atayna, c'una non sai loindana ni vezina, si vol amar, vas vos no si'aclina; mas vos, amics, etz ben tant conoisens que ben devetz conoisser la plus fina, e membre vos de nostres covinens.
Vou cantar tudo que eu não gostaria

I

Vou cantar tudo que eu não gostaria, tanto este amigo só me contraria, pois amo mais do que a maior poesia; mas ele não vê charme ou cortesia, quando sou linda, honrada, inteligente; já ele que me enganava e me traía, que eu merecia se te fosse ausente. II

Vem, me conforta com a tua presença, amigo, pois eu nunca fiz ofensa:

te amo mais que Seguis amou

Valença, e adoro que de amor só eu te vença, pois meu amigo é sempre o mais valente:

me deu orgulho em fala e benquerença, e é mais querido do que toda a gente. III

Me assombro se o teu coração se orgulha

comigo, amigo, e isso mais me embrulha:

injusto é que te roube uma fagulha que tanto fala até que te debulha; mas lembre bem que já não é recente o nosso amor. E que eu não seja a pulha,

por Deus, que definhou o amor crescente.

IV

$O$ valor que em teu peito assim se aninha, com tua honra mais me desalinha, não sei de alguém distante ou mais vizinha que quer amar contigo e não definha, meu amigo, você bem sabe e sente quem delas é mais fina e mais certinha, e lembre o nosso pacto penitente. 
V

Valer mi deu mos pretz e mos paratges

e ma beutatz e plus mos fins coratges, per q'ieu vos mand lai on es vostr'estatges

esta chanson, que me sia messatges: e voill saber, lo mieus bels amics gens, per que vos m'etz tant fers ni tant salvatges;

no sai si s'es orguoills o mal talens. $\mathrm{VI}$

Mais aitan plus vuoill li digas, messatges, q'en trop d'orguoill an gran dan maintas gens. (RIQUER, 1975, p. 800802)
$\mathrm{V}$

Tenho valor por honra e por linhagem pela beleza e ainda por coragem; por isso, envio até tua paragem esta canção que serve de mensagem; pergunto, belo amigo e boa gente, por que você comigo é tão selvagem, tão orgulhoso, ou tão indiferente. $\mathrm{VI}$

Mas pode lhe dizer, minha mensagem, que muito orgulho é mágoa a muita gente. $^{1}$

Percebe-se que Beatriz atenta-se para as regras trovadorescas e do amor cortês e ocupa o lugar da amiga que coloca o sentimento amoroso em uma posição acima da própria poesia, como pode-se observar na primeira estrofe. Ao afirmar que ama mais do que a maior poesia, ela se insere na tradição que mais do que cantar o amor a outrem, canta ao próprio Amor.

Na sequência, ela utiliza outras figuras poéticas comuns no trovadorismo que versam sobre as qualidades da dama amada que é a mais bela, que contém maior mesura e, assim, maior cortesia e, portanto, não se compara a nenhuma outra e se faz merecedora do amor do trovador. No entanto, todas essas qualidades que a trovadora possui, uma vez que ela é nobre, como vai afirmar na penúltima estrofe, não são 
suficientes para que o seu amigo esteja presente e dedique o seu amor a ela.

Ainda assim, a autora pede a presença do amigo e confirma seu amor a ele, fazendo uma comparação e dizendo que o ama mais do que Seguis a Valença ${ }^{21}$. Dessa forma, ela coloca-se no lugar no amante masculino e o nome Valença é duplamente associado ao do amigo, por meio da comparação em si e da relação gramatical que conecta o nome dela com o a maior virtude do amante: valentia (BRUCKNER, 1992, p. 881), como ela afirma no decorrer da segunda estrofe. Para Segismundo Spina (1991, p. 125), o fato de a mulher se comportar social e eticamente como o trovador diante da dama, seria um testemunho do convencionalismo do amor cortês. No entanto, a cantiga desorganiza o convencionalismo, uma vez que a mulher enaltecida na cantiga não é uma imagem idealizada e transcendente, mas se confunde com o eu-lírico que efetivamente é representado por uma mulher e não por um trovador que escreve a partir dessa perspectiva, como ocorre no trovadorismo ibérico.

Ademais, é possível perceber que tanto a trovadora como o amante compartilham atributos da dama cortejada no amor cortês, de modo a subverter o fundamento do gênero,

21 Novela medieval perdida de Arnaut de Maruelh (1170-1200). 
uma vez que o trovador sempre é inferior à dama. De certa forma, essa relação persiste, uma vez que a trovadora faz questão de afirmar a sua alta linhagem, conservando a imagem da superioridade da dama. Há, portanto, um jogo de palavras e de recursos literários que fundamentam uma constante trocas de papeis e, ao mesmo tempo, a atuação de ambos nos dois, que contribui para repensar as estruturas da escrita sob os moldes do amor cortês, colaborando para compreendê-lo de uma maneira mais ampla, associando as mulheres à prática da escrita e amorosa, inserindo a dama, por vezes idealizada, na realidade, como um ser concreto e que discursa sobre sua posição social e seus desejos.

É interessante notar que essa valorização de suas próprias qualidades são um diferencial nas produções de Beatriz, assim como a exaltação de seu status dentro da sociedade da região do Langue d'Oc, o que também pode ser evidenciado na sua representação imagética no Cancioneiro K (mostrado acima), a qual é apresentada com grande prestígio e sinais de riqueza, corroborando seu status nobiliárquico.

Ainda que o número de cantigas que restaram das trovadoras seja ínfimo perto do corpus trovadoresco como um todo, a representatividade de Beatriz contribui para 
identificar um "despertar de uma soma significativa de mulheres que, fosse na literatura ou na realidade vivida, rompiam com os padrões sociais vigentes" (PEREIRA, 2013, p. 90). O caso da trovadora provençal é instigante porque ela coloca a realidade e a literatura em simbiose, dando voz à mulher, uma vez que é ela quem desenvolve a narrativa amorosa, assumindo, assim, o papel de dirigente da relação.

A composição também revela que a literatura estava vívida na cultura cortês, como demonstra a intertextualidade identificada na referência ao romance de Arnaut de Maruelh que se perdeu. Em sua outra composição, Estat ai em greu cossirier, Beatriz também utiliza do componente intertextual para desenvolver sua narrativa:

$\begin{array}{ll}\text { Estat ai en greu cossirier } & \text { Tenho sofrido uma aflição } \\ \text { I } & \text { I } \\ \text { Estat ai en greu cossirier } & \text { Tenho sofrido uma aflição } \\ \text { per un cavallier q'ai agut, } & \text { por cavaleiro que passou; } \\ \text { e voill sia totz temps saubut } & \text { quero que saiba como estou } \\ \text { cum eu l'ai amat a sobrier; } & \text { atribulada de paixão; } \\ \text { ara vei q'ieu sui trahida } & \text { hoje sei que fui traída } \\ \text { car eu non li donei m'amor, } & \text { por não ter dado o meu amor, } \\ \text { don ai estat en gran error } & \text { pois é meu erro e meu pudor } \\ \text { en lieig e qand sui vestida. } & \text { estar na cama vestida. } \\ \text { II } & \text { II } \\ \text { Ben volria mon cavallier } & \text { Queria ter ao rés do chão } \\ \text { tener un ser e mos bratz but, } & \text { o cavaleiro ainda nu, } \\ \text { q'el s'en tengra per ereubut } & \text { ou que ele achasse mais azul } \\ \text { sol q'a lui fezes cosseillier; } & \text { se transformar em meu colchão; } \\ \text { car plus m'en sui abellida } & \text { estou mais enlouquecida } \\ \text { no fetz Floris de Blanchaflor: } & \text { do que Floris por Brancaflor: } \\ \text { eu l'autrei mon cor e m'amor } & \text { eu dei meu peito e meu amor, } \\ \text { mon sen, mos huoills e ma vida. } & \text { dei meu senso, olhar e vida. }\end{array}$


III

Bel amics, avinens e bos, cora $\bullet$ us tenrai e mon poder?

e que jagues ab vos um ser e qe $\bullet$ us des um bais amoros! Sapchatz, gran talan n'auria qe us tengues en luoc del marit, ab so que m'aguessetz plevit de far tot so qu'eu volria. (RIQUER, 1975, p. 798-799)
III

Meu belo amigo encantador, quando você será só meu? Deitados na noite, no breu, pra dar os beijos deste amor! Você sabe: eu amaria trocar meu homem por você, e só precisa prometer fazer tudo que eu queria. ${ }^{2}$

Nessa cantiga há a referência a Floris e Brancaflor, personagens do romance Floire et Blancheflor do século XII que foi traduzido para o inglês no século seguinte. Brancaflor também é personagem do romance incompleto Perceval (ou Le Conte du Graal), de Chrétien de Troyes (1140-1190), considerado o primeiro e o maior romancista francês da Idade Média. Essa referência indica a rica transmissão cultural existente no medievo, da qual Beatriz fazia parte como audiência e disseminadora, uma vez que utiliza as referências em suas composições. Nessa cantiga, a autora compara mais uma vez seu amor com os dois personagens, utilizando-se da forma hiperbólica de definir o amor na produção trovadoresca.

As utilizações intertextuais não são exclusivas da trovadora que também utilizada outras fórmulas do amor cortês, como a referência à incompatibilidade entre o amor e o casamento, já que ela confessa amar um cavaleiro que não é seu marido. 
Ao escrever de acordo com certas regras, ela demonstra seu conhecimento da tradição trovadoresca e insere-se nela. Ao mesmo tempo, ela utiliza essas construções de certa forma estanques, pois se constituem com estruturais do gênero, como um degrau para desenvolver a singularidade de sua criação, como é o caso de trovar de forma explícita que deseja o seu cavaleiro ainda nu e, mais, que ele se transforme em seu colchão. Essa é uma passagem bastante interessante, pois ao utilizar o advérbio de tempo ainda, ela nos dá a informação de que essa ação já aconteceu em algum momento e ela quer que ocorra novamente a ponto do seu amado tornar-se o seu colchão. Ou seja, ela está falando do desejo de estar na cama com seu amigo, de efetivar a relação amorosa mais uma vez, pois o ainda nu nos dá a informação de que a relação amorosa já foi efetivada em algum momento. E, ao mencionar que deseja que seu amado se torne o seu colchão, poderia ser um indício da posição em que essa relação se efetuaria, já que um colchão serve para que nos deitemos em cima dele, ela então ficaria em cima do seu amigo, apontando para mais uma prática em que a mulher não era necessariamente passiva, afirmando assim estar no controle da relação, como também sugere o último verso da cantiga na qual a trovadora diz esperar que seu cavaleiro faça tudo que ela queira. 
Ainda que tenhamos que nos deter que se trata de um discurso literário, este não surge do nada, mas está inserido em um contexto e pode revelar um desejo ou uma possibilidade de que as relações se desenvolvam de variadas maneiras. Além disso, sugere uma identificação de gênero, uma vez que a trovadora escreve a partir do lugar de uma mulher e não se corporizando em outro gênero como o fazem alguns trovadores ibéricos ao escreverem suas cantigas de amigo. Sendo assim, as cantigas de amigo galego-portuguesas apontam para uma interpretação do que os homens pensam sobre as mulheres, seus desejos e suas possíveis ações. Por sua vez, Beatriz escreve a partir de um lugar que lhe pertence e que lhe empresta inspiração e condições para a escrita.

Diante disso, tem-se que as obras de Beatriz de Dia contribuem para pensar o amor cortês para além da idealização e como um jogo de controle do desejo. Ainda que esses sejam elementos importantes, há por meio desse discurso amoroso e de sociabilidade, a afirmação da sexualidade e do desejo que ela se realize. O fato disso ser expressado por uma mulher é de extrema importância, pois contribui para desconstruir o discurso homogêneo sobre sua participação na sociedade e na sociabilidade 
medieval. É claro que a misoginia não deixou de existir e a identificação na primeira cantiga de referências que afirmam a origem da trovadora podem sugerir que isso era necessário justamente como uma forma de embate a esse tipo de pensamento que ainda persiste e é responsável por ela e tantas outras mulheres estarem à margem dos cânones história e da literatura.

\section{REFERÊNCIAS}

ANGLADE, Joseph. Grammaire de l'ancien provençal ou ancienne langue d'oc: phonétique et morphologie. Paris: Librairie Klincksieck, 1921. Disponível em: https://gallica.bnf.fr/ark:/12148/bpt6k255748j/f46.image. Acesso em: 1 de Março de 2021.

BARROS, José D'Assunção. O amor cortês - suas origens e significados. Raído, Dourados, v. 5, n. 9, p. 195-216, jan./jun. 2011. Disponível em: https://ojs.ufgd.edu.br/index.php/Raido/article/viewFile/979/811. Acesso em: 10 de fev. de 2021.

$\mathrm{BEC}$, Pierre. La langue occitane. Paris: Presses Universitaires de France, 1986.

BENTES, Roberta. Texto e imagem nos cancioneiros occitanos Mss. BnF, Fr. 854 e 12.473. 2019. 119f. Dissertação (Mestrado em História) - Programa de Pós-graduação em História, Universidade Federal do Paraná, Curitiba, 2019. Disponível em: https://acervodigital.ufpr.br/ bitstream/handle/1884/63383/R\%20-\%20D\%20-\%20ROBERTA\%20 MACEDO\%20DA\%20GAMA\%20BENTES. pdf? sequence=1\&isAllowed $=\mathrm{y}$. Acesso em: 1 de março de 2021.

BENTES, Roberta. O fin'amors occitano e a sua não idealização. Sacralidades Medievais, 2020. Disponível em: https:// sacralidadesmedievais.godaddysites.com/textos-semanais/f/ofin\%E2\%80\%99amors-occitano-e-a-sua-n\%C3\%A3o-idealiza\%C3\%A7 
\%C3\%A3o?blogcategory=ESCRITA+DA+HIST\%C3\%93RIA-LITERATURA. Acesso em: 2 de março de 2021.

BLAKESLEE, Merritt. The Countess of Dia. In: WILSON, Katharina. An Encyclopedia of Continental Women Writers. Vol. 1. New York e London: Garland Publishing, 1991.

BRUCKNER, Matilda Tomaryn. Fictions of the Female Voice: The Women Troubadours. Speculum, v. 67, n. 4, out, 1992. Disponível em: http:// www.jstor.org/stable/2863471. Acesso em: $28 \mathrm{de} \mathrm{fev.} \mathrm{de} 2021$. BRUCKNER, Matilda; SHEPARD, Laurie; WHITE, Sarah. Songs of the Women Troubadours. New York e London: Routledge, 2000.

BRUN, Sandrine. Les femmes musiciennes aux XIIe-XIIle siècles: le cas des trobairitz. 2014. 208f. Dissertação (Mestrado em Ciências da Informação e das Bibliotecas) - Université de Lyon, Lyon, 2014.

BURGWINKLE, William. The chansonniers as books. In: KAY, Sarah; GAUNT, Simon. The Troubadours - An Introduction. Cambridge: University of Cambridge Press, 1999.

CHANSONNIER PROVENÇAL [CHANSONNIER K] - Ms. BnF, Fr. 12.473. Bibliothèque National de France. [s.d.]. Disponível em: https://gallica. bnf.fr/ark:/12148/btv1b60007960/f5.image. Acesso em: 1 de março de 2021.

DUBY, Georges. Idade Média, idade dos homens: Do amor e outros ensaios. São Paulo: Companhia das Letras, 2011.

DUC DE LA SALLE DE ROCHEMAURE. Les Troubadours Cataliens. Tome I. Aurillac: Imprimerie moderne, 1910, p. 416. Disponível em: https://archive.org/details/lestroubadoursca01lasa/page/n3/ mode/2up?view=theater. Acesso em: 1 de março de 2021. EPISTOLAE: MEDIEVAL WOMEN'S LETTERS. Eleanor Rainha Da Inglaterra - Carta de Leonor (1199). Disponível: https://epistolae.ctl.columbia.edu/ letter/1329.html. Acesso em: 24 de fev. de 2021.

FLORI, Jean. A cavalaria: a origem dos nobres guerreiros da Idade Média. São Paulo: Madras, 2005. 
HUCHET, Jean-Charles. Les femmes troubadours ou la voix critique. Littérature, Paris, n. 51, 1983.

KLAPISCH-ZUBER, Christiane. Masculino/feminino. In: LE GOFF, Jacques; SCHMITT, Jean-Claude (Coords.) Dicionário analítico do Ocidente Medieval: vol. 2. São Paulo: Editora da Unesp, 2017. LE GOFF, Jacques. Heróis e maravilhas da Idade Média. Petrópolis: Vozes, 2011.

MARCHELLO-NIZIA, Christine. Introduction. In: POIRION, Daniel (Org.). Tristan et Yseut. Les prèmieres versions européenes. Paris: Gallimard, 1995, p. XXXIX.

MENDES, Ana Luiza. O trovar coroado de Dom Dinis: modelo de racionalidade artística e identitária no trovadorismo galego-português. 2018. 216f. Tese (Doutorado em História). Universidade Federal do Paraná, Curitiba, 2018.

PATTISON, Walter. The life and Works of the Troubadour Raimbaut d'Orange. Minneapolis: University of Minnesota Press, 1952.

PEREIRA, Nilton Mullet. Fin amour: as condições de existência no mundo medieval. In: ALMEIDA, Cybele Crossetti de; TEIXEIRA, Igor Salomão. Reflexões sobre o medievo III: práticas e saberes no ocidente medieval. São Leopoldo: Oikos, 2013.

RÉGNIER-BOHLER, Danielle. Amor cortês. In: LE GOFF, Jacques; SCHMITT, Jean-Claude. Dicionário analítico do ocidente medieval: vol. 1. São Paulo: Unesp, 2017.

RIQUER, Martin. Los trovadores: Historia literária y textos. Vol. 2. Barcelona: Editora Planeta, 1975.

SCHULTZ-GORA, Oskar. Die provenzalischen Dichterinnen: Biographieen und Texte nebst Anmerkungen und einer Einleitung. Leipzig: Gustav Fock, 1888.

SPINA, Segismundo. A lírica trovadoresca. São Paulo: Ed. EDUSP, 1991.

STEPHENS, Sonya (Ed.). A history of women's writing in France.

Cambridge: Cambridge University Press, 2000. 


\section{(Footnotes)}

1 Tradução de Guilherme Gontijo Flores.

2 Tradução de Guilherme Contijo Flores.

Ana Luiza Mendes

Doutora (Universidade Federal do Paraná - UFPR, 2018).

Graduanda Universidade Tecnológica Federal do Paraná (UTFPR).

http://lattes.cnpq.br/5462463163096319

https://orcid.org/0000-0002-2291-1417

analuizam982@gmail.com

Roberta Bentes

Mestra (UFPR)

Participa do Núcleo de Estudos Mediterrâneos (UFPR) e do "Grupo de Estudos sobre Britânia, Irlanda e Ilhas do Arquipélago Norte na Antiguidade e Medievo - Insulæ".

http://lattes.cnpq.br/4938697595727690

https://orcid.org/0000-0002-6602-5759

roberta.bentes@gmail.com 